\section{Scottish provisions for vulnerable witnesses}

Cooper and Grace discussed the special measures for vulnerable witnesses in England and Wales ${ }^{1}$. We hope to provide the context of these provisions in Scotland.

In Scottish legislation an individual may be deemed vulnerable when giving evidence if they are under 18 or have a mental disorder which may affect the quality of this evidence. Under the Victims and Witnesses (Scotland) Act 2014 'standard special measures' are given for vulnerable witnesses. In contrast to England and Wales, these measures also apply to those who are accused. The following measures are included in the Criminal Procedure (Scotland) Act 1995 (3) (Section 271H).

'Taking of evidence by a commissioner': an individual appointed by the courts takes the evidence.

'Use of a live television link': the witness gives evidence from somewhere outside the courtroom by means of a live television link, not necessarily within the court building.

'Use of a screen': the accused is physically concealed from the witness, although the court ensures that the accused can watch and hear the witness giving evidence.

'Use of a supporter': supporters can be selected by witnesses or on their behalf. Their role is to support witnesses while the witnesses give evidence. If they also have to give evidence, they must do so before acting as supporters.

'Giving evidence in chief in the form of a prior statement': a statement by the witness is lodged in evidence without the witness having to speak in court.

If it is felt that these measures are necessary, a Vulnerable Witness Application must be lodged by those who are citing the witness. This application includes which measures are being requested and the views of the witness, including any carer if possible. The court has the final decision on which measures are most appropriate.

In contrast to England and Wales legislation, the Vulnerable Witnesses (Scotland) Act 2004 put an end to the competence test for witnesses. Competency is set out in England and Wales legislation under the Youth Justice and Criminal Evidence Act 1999. The advantage of removing this test is that it allows the judge or jury to determine the witness's reliability, rather than a test which did not necessarily ensure the truthfulness of their evidence. This ensures that vulnerable people have the opportunity to be heard.

It is important that practitioners working with vulnerable witnesses who may be appearing in the Scottish courts are aware of these procedures, as their input could drastically change a witness's experience of the court. Psychiatrists are in a position to advise on optimum conditions to aid a patient's mental state, and in so doing not only ensure a fair legal process, but also a legal process that is as stress-free as possible.

Michael W. Turner, Core Trainee in Psychiatry, NHS Grampian, Aberdeen, UK; email: michael.turner@nhs.net, Alasdair D. Forrest, ST4 in Forensic Psychiatry and Medical Psychotherapy, NHS Grampian, and Daniel M. Bennett, Honorary Senior Lecturer and Consultant Forensic Psychiatrist, University of Aberdeen, NHS Grampian

1 Cooper P, Grace J. Vulnerable patients going to court: a psychiatrist's guide to special measures. BJPsych Bull 2016; 40: 220-2.

doi: $10.1192 / p b .40 .6 .347$

\section{Voting and mentally disordered offenders: a Scottish (and post-Brexit) supplementary}

Rees and Reed advocate expanding the electoral franchise to convicted mentally disordered offenders, ${ }^{1}$ referring to a judgment of the European Court of Human Rights. The current prime minister has spoken in favour of withdrawing from the jurisdiction of the Court ${ }^{2}$ - a possibility in the era of Brexit so their suggestion is unlikely to come to pass. However, they also provide a helpful summary of which mentally disordered offenders have the right to vote. We would like to reply with a summary of the situation in Scotland, which was notably omitted from their editorial.

The Representation of the People Act 1983 was amended in 2000 and has specific provisions for Scotland. Patients detained on civil provisions of the Mental Health (Care and Treatment) (Scotland) Act 2003 are eligible to vote by virtue of the amended 1983 Act, as are those subject to guardianship orders under the Adults with Incapacity (Scotland) Act 2000. Remand prisoners and civil prisoners are also eligible to vote.

Those at the pre-trial stage in Scotland may be detained in hospital on Assessment Orders or Treatment Orders. As untried persons, they can vote. By virtue of Section 3A(3) of the amended 1983 Act, those subject to one of the various psychiatric disposals are ineligible to vote. These are a Compulsion Order, which authorises hospital treatment, or a Hospital Direction, which authorises hospital treatment and return to prison when well enough, or a Compulsion Order and Restriction Order, which involves special restrictions. Those found unfit for trial and subject to a temporary Compulsion Order cannot vote, and neither can those admitted from prison on a Transfer for Treatment Direction.

That is all similar to England. However, in Scotland, patients can be subject to a unique form of community-based criminal detention without a precise English analogue. This is a Compulsion Order without a provision under Section $57 \mathrm{~A}(2)(8)(a)$ to authorise detention in hospital. Such patients are ineligible to vote by a strict reading of the amended 1983 Act, which was probably not written with such a scenario in mind. Conditionally discharged restricted patients, living in the community, are also ineligible.

Even if the current position in Scotland is clear, the future is less clear. The Scotland Act 2016 has expanded the legislative remit of the Scottish Parliament with respect to electoral law, and the voting age for local and Holyrood elections has been lowered to 16, giving different franchises for elections to Holyrood and to Westminster.

So Holyrood could now legislate to expand the franchise for Scottish elections. However, there may be little appetite for Rees and Reed's recommendations, since the Scottish Parliament did not allow prisoners to vote in the 2014 independence referendum - a decision upheld in the Court of Session and the Supreme Court of the United Kingdom. ${ }^{3}$

Alasdair D. Forrest, ST4 in Forensic Psychiatry and Medical Psychotherapy, NHS Grampian, Aberdeen, UK; email: alasdair.forrest@nhs.net, Michael W. Turner, Core Trainee in Psychiatry, NHS Grampian, and Daniel M. Bennett, Honorary Senior Lecturer and Consultant Forensic Psychiatrist, University of Aberdeen, NHS Grampian

1 Rees G, Reed J. Patients or prisoners? Time to reconsider the voting rights of mentally disordered offenders. BJPsych Bull 2016; 40: 169-72. 